\title{
BMJ Open Magnitude of internalised stigma and associated factors among people with bipolar disorder at Amanuel Mental Specialized Hospital, Addis Ababa, Ethiopia: a cross-sectional study
}

To cite: Shumet S, W/ Michele B, Angaw D, et al. Magnitude of internalised stigma and associated factors among people with bipolar disorder at Amanuel Mental Specialized Hospital, Addis Ababa, Ethiopia: a crosssectional study. BMJ Open 2021;11:e044824. doi:10.1136/ bmjopen-2020-044824

- Prepublication history for this paper is available online To view these files, please visit the journal online (http://dx.doi. org/10.1136/bmjopen-2020044824).

SS and NA are joint first authors.

Received 17 September 2020 Revised 10 March 2021 Accepted 15 March 2021

Check for updates

(C) Author(s) (or their employer(s)) 2021. Re-use permitted under CC BY-NC. No commercial re-use. See rights and permissions. Published by BMJ.

For numbered affiliations see end of article.

Correspondence to Mr Shegaye Shumet; shumetshegaye@yahoo.com

\section{ABSTRACT}

Objectives To assess the magnitude of internalised stigma and associated factors among patients with bipolar disorder attending the outpatient department of Amanuel Mental Specialized Hospital, Addis Ababa, Ethiopia.

Design Institution-based cross-sectional study design.

Setting Amanuel Mental Specialized Hospital, Addis Ababa, Ethiopia.

Participants We recruited about 418 participants using systematic sampling technique for an interview during the study period.

Measurement Data were collected by face-to-face interviews. Internalized Stigma of Mental IIIness scale was used to measure internalised stigma. The Rosenberg Self-Esteem Scale and the 0slo-3 Social Support were instruments used to assess the associated factors. Bivariate and multivariate logistic regressions were performed to identify factors associated with the outcome variable. ORs with $95 \% \mathrm{Cl}$ were computed to determine the level of significance.

Results The magnitude of internalised stigma was $24.9 \%$ (95\% Cl: $21.2 \%$ to $28.9 \%)$. In the multivariate analysis, unemployed (adjusted OR (AOR) $=2.3,95 \% \mathrm{Cl}: 1.0$ to 5.0), unable to read and write ( $\mathrm{AOR}=3.3,95 \% \mathrm{Cl}: 1.05$ to 10.7), poor social support (AOR=5.3, 95\% Cl: 1.9 to 15.0), $\geq 4$ previous hospitalisations due to bipolar disorder (AOR=2.6, $95 \% \mathrm{Cl}: 1.1$ to 6.1$)$ and low self-esteem $(A 0 R=2.4,95 \% \mathrm{Cl}$ : 1.1 to 5.1 ) had a significant association with internalised stigma.

Conclusions One in four patients with bipolar disorder reported high internalised stigma. Unemployment, low educational status, low self-esteem, poor social support and being hospitalised more than three times before were significantly associated with internalised stigma. Thus, a stigma-reduction programme focusing on self-esteem improvement and psychological health of patients to increase their stigma resistance to counteracting effects of internalised stigma is essential.

\section{INTRODUCTION}

The WHO considers the stigma of mental illness as a global health problem because it has a direct effect on the overall quality of life

\section{Strengths and limitations of this study}

- The limitation of the study emanates from its crosssectional design, which might not show causal relationship.

- Social and recall biases might have occurred among patients while interviewing them using the questionnaire.

- An internalised stigma scale can be used for future studies because it had good internal consistency in this study.

of people with mental illness. ${ }^{12}$ Mental health research identified different inter-related levels of stigma, including internalised stigma. ${ }^{3}$ Internalised stigma is a phenomenon of accepting and incorporating a negative stereotype about mental illness into the identity of people. ${ }^{45}$

Bipolar disorder is one of the most severe mental illnesses, which is characterised by fluctuating periods of mania and depression. In severe episodes of the disorder, it contains delusions and hallucinations. ${ }^{6}$ When the onset of the illness is early in age, severe and chronic, its disability impact is high. ${ }^{7}$ It is the sixth cause of disability. ${ }^{8}$ Studies in developed and developing countries showed that $18.5 \%-$ $46 \%$ of patients with bipolar disorder have internalised stigma. ${ }^{4-15}$ For example, the magnitude of internalised stigma has been $38.7 \%$ in Kerala, India, ${ }^{14} 21.6 \%$ and $33.7 \%$ in Nigeria. ${ }^{1316}$ Because of internalised stigma, patients might have a reduction of morality, increased avoidance behaviours and reduced social functioning. ${ }^{17-19}$ It also has an impact on an individual's decision to seek treatment and create similar barriers to life opportunities and achievements. ${ }^{20} 21$ Moderating and risk factors for internalised stigma among 
patients with bipolar disorder have been sex, middle age, low level of education, unemployment, severity of depression, perceived social support, family history of mental illness, number of previous hospitalisations, longer duration of illness and low-self esteem. ${ }^{9-11}$ 14-16 2223 Patients' belief about the cause of the illness is more frequently associated with stigmatised attitude, and results in less likely seeking the recommended treatment. ${ }^{24}$ Patients with high internalised stigma have lower adherence to their treatment so the condition of the illness becomes more severe. ${ }^{25}$ Many patients with bipolar disorder have discontinued their prescribed medications and are rehospitalised, which results in a high cost for the healthcare system. Even though internalised stigma is high and has different impacts, there are no study findings which show its magnitude among patients diagnosed with bipolar disorder in Ethiopia. Therefore, determining the magnitude and associated factors of internalised stigma of patients diagnosed with bipolar disorder is important to control bipolar symptoms, decrease the burden of relapse and regain basic life functioning which all contribute to improving patients' quality of life.

\section{Objective}

The aim of this study was to assess the magnitude of internalised stigma and associated factors among people diagnosed with bipolar disorder at Amanuel Mental Specialized Hospital (AMSH), Addis Ababa, Ethiopia, 2016.

\section{METHODS AND MATERIALS \\ Study setting and period}

An institution-based cross-sectional study design was conducted among patients diagnosed with bipolar disorder who had follow-ups at AMSH in Addis Ababa, Ethiopia between May and June 2016. It was the first mental health-specialised hospital that started mental health services in Ethiopia. It gives treatment services for patients coming with different mental health problems in the outpatient and inpatient setting at the moment.

\section{Study population}

The study included patients aged 18 years and above during data collection in the outpatient department of the hospital. Patients with positive symptoms/acutely disturbed, unable to communicate and with hearing problem were excluded.

\section{Sample size determination and technique}

We determined the sample size by using the single population proportion formula with the assumptions of $50 \%$ prevalence of internalised stigma: $\mathrm{p}=0.5, \mathrm{Z}=1.96$ (standard normal distribution), 95\% CI, $\alpha=0.05$ and a $10 \%$ non-response rate. Accordingly, a representative/probabilistic sample was calculated to be 423 . Participants were recruited randomly by using the systematic sampling technique. The sampling interval was determined by dividing the total study population who had follow-up during the data collection period by the total sample size, then the starting point was randomly selected.

\section{Study variables}

The dependent variable was internalised stigma measured by the Internalized Stigma of Mental Illness (ISMI) scale. We measured internalised stigma as a dichotomous variable (yes/no). Independent variables included sociodemographic factors, psychosocial factors and clinical variables (age at the onset of the illness, number of episodes, duration of the treatment and number of previous hospitalisations).

\section{Data sources and measurement}

Data were collected by face-to-face interviews using a semistructured questionnaire administered by six mental health professionals using the Amharic version of the tool for a month. The interviews were carried out after the patients have been seen by their physician. The questionnaire was designed in English and translated to Amharic and back to English to maintain consistency. Though the translated version of the questionnaire was not validated, a pretest was done prior to the actual data collection time. Data collectors were trained on introduction to bipolar disorder and stigma, how to interview and explain unclear questions. Furthermore, they were made aware about ethical aspects of the study, such as confidentiality/ anonymity, data management and securing respondents' informed consent for participation.

Internalised stigma was measured using the 29-item ISMI scale which had five domains, namely alienation, stereotype endorsement, discrimination experience, social withdrawal and stigma resistance. It had a Likert response options ranging from (1) 'strongly disagree' to (4) 'strongly agree', and the total score was calculated by summing the 29 items $^{4}$ and a cut-off $\geq 2.5$, that is, study participants had internalised stigma. ${ }^{4}$ We adapted the tool from a study conducted in Jimma, Ethiopia. ${ }^{23}$ It showed a high internal consistency and reliability $(\kappa=0.89)$. We conducted a reliability analysis for the translated Amharic version of the tool and showed a high score (Cronbach's $\alpha=0.93$ ).

Social support was measured using the Oslo-3 Social Support Scale with scores ranging from 3 to 14: 3-8=poor social support; 9-11=intermediate social support and $12-14=$ strong social support. ${ }^{26}$

Self-esteem was assessed by the Rosenberg Self-Esteem Scale and categorised into low and high self-esteem score. ${ }^{27}$

Items on sociodemographic factors (age, sex, ethnicity, marital status, religion, educational and occupational status) were adopted from a variety of literature.

\section{Data processing and analysis}

Data were entered into EPI Info V.7 after checking completeness and then exported to SPSS V.20 for analysis. We computed descriptive, bivariate and multivariate 
logistic regression analyses to see the frequency distribution and to test the association between independent and dependent variables, respectively. Factors associated with internal stigma were selected during the bivariate analysis with a $p$ value of $<0.2$ for further analysis in the multivariable logistic regression analysis. In the multivariable logistic regression analysis, the strength of association was evaluated using the adjusted OR (AOR) with a 95\% CI, and a $\mathrm{p}$ value less than 0.05 .

\section{Patient and public involvement}

Our study participants were not involved in the study design and recruitment.

\section{RESULTS}

A total of 418 participants took part with a response rate of $98.8 \%$. From five participants, four did not voluntarily participate and one discontinued the interview. The mean (SD) age of the respondents was 34.29 (10.4) years, and $164(39.2 \%)$ were in the age range of 25-34 years; $216(51.7 \%)$ were male; $223(53.3 \%)$ were single and $140(33.5 \%)$ were in secondary school. The majority, $311(74.4 \%)$, of the participants were living in an urban setting. According to the World Development Report 2010, $180(43.1 \%)$ were living above poverty benchmark (table 1).

Regarding the clinical characteristics of participants, the majority, 255 (61.0\%), developed the disorder before 25 years of age, and 157 (37.6\%) have had the illness for more than 10 years. Of the respondents, $220(52.6 \%)$ had treatment duration of less or equal to 6years, and 251 $(60 \%)$ of them had more than two episodes. In terms of previous hospitalisation, $218(52.2 \%)$ of the patients were hospitalised because of the disorder.

A small number, $45(10.8 \%)$, of the participants were hospitalised $\geq 4$ times previously, and $310(74.2 \%)$ had manic episodes. About 190 (45.5\%) took traditional treatment for their illness; 119 (28.5\%) had a family history of mental illnesses and $144(34.4 \%)$ attempted suicide. Of the total 418 participants, $233(55.7 \%)$ discontinued their medication and $25(10.7 \%)$ were discontinuing because of perceived stigma. Regarding psychosocial factors, 176 $(42.1 \%)$ of the participants had poor social support, and $133(31.8 \%)$ had low self-esteem (table 2 ).

\section{Magnitude of internalised stigma}

The prevalence of internalised stigma among participants was $24.9 \%$, with $95 \%$ CI $(21.2 \%$ to $28.9 \%)$. Regarding the subscales of ISMI, 151 (36.1\%), $71(17.0 \%), 154$ $(36.8 \%)$ and $109(26.1 \%)$ of the respondents had internalised stigma score in alienation, stereotype endorsement, discrimination experience and social withdrawal, respectively.

\section{Factors associated with internalised stigma}

To determine the association of independent variables with internalised stigma, bivariate and multivariate binary
Table 1 Frequency and percentage of patients with bipolar disorder on follow-ups at Amanuel Mental Specialized Hospital, Addis Ababa, Ethiopia, $2016(n=418)$

\begin{tabular}{|c|c|c|c|}
\hline Variables & Category & Frequency & Per cent \\
\hline \multirow[t]{4}{*}{ Age } & $18-24$ & 66 & 15.8 \\
\hline & $25-34$ & 164 & 39.2 \\
\hline & $35-44$ & 120 & 28.7 \\
\hline & $\geq 44$ & 68 & 16.3 \\
\hline \multirow[t]{2}{*}{ Sex } & Male & 216 & 51.7 \\
\hline & Female & 202 & 48.3 \\
\hline \multirow[t]{4}{*}{ Religion } & Orthodox & 230 & 55.0 \\
\hline & Muslim & 94 & 22.5 \\
\hline & Protestant & 82 & 19.6 \\
\hline & Others & 12 & 2.9 \\
\hline \multirow[t]{3}{*}{ Marital status } & Single & 223 & 53.3 \\
\hline & $\begin{array}{l}\text { Divorced/ } \\
\text { widowed }\end{array}$ & 65 & 15.6 \\
\hline & Married & 130 & 31.1 \\
\hline \multirow[t]{4}{*}{ Ethnicity } & Amhara & 151 & 36.1 \\
\hline & Oromo & 120 & 28.7 \\
\hline & Gurage & 75 & 17.9 \\
\hline & Others & 72 & 17.2 \\
\hline \multirow[t]{4}{*}{ Educational status } & $\begin{array}{l}\text { Unable to read } \\
\text { and write }\end{array}$ & 62 & 14.8 \\
\hline & Primary & 103 & 24.6 \\
\hline & Secondary & 140 & 33.5 \\
\hline & $\begin{array}{l}\text { College and } \\
\text { above }\end{array}$ & 113 & 27.0 \\
\hline \multirow[t]{2}{*}{ Residency } & Rural & 107 & 25.6 \\
\hline & Urban & 311 & 74.4 \\
\hline \multirow[t]{2}{*}{ Currently working } & Yes & 277 & 66.27 \\
\hline & No & 141 & 33.73 \\
\hline \multirow[t]{4}{*}{ Type of occupation } & $\begin{array}{l}\text { Government } \\
\text { employee }\end{array}$ & 58 & 13.9 \\
\hline & Farmer & 45 & 10.8 \\
\hline & $\begin{array}{l}\text { Private } \\
\text { enterprise }\end{array}$ & 121 & 28.9 \\
\hline & Others & 53 & 12.7 \\
\hline \multirow[t]{3}{*}{$\begin{array}{l}\text { Household monthly } \\
\text { income }\end{array}$} & $\begin{array}{l}\text { Extreme } \\
\text { poverty }\end{array}$ & 113 & 27.0 \\
\hline & $\begin{array}{l}\text { Poverty } \\
\text { benchmark }\end{array}$ & 125 & 29.9 \\
\hline & $\begin{array}{l}\text { Above poverty } \\
\text { benchmark }\end{array}$ & 180 & 43.1 \\
\hline
\end{tabular}

logistic regression analyses were carried out. In the bivariate analysis, factors including current work status, educational status, residence and marital status, patients taking traditional treatment, duration of the illness, number of 
Table 2 Frequency and percentage of clinical and psychosocial factors among people with bipolar disorder at Amanuel Mental Specialized Hospital, Addis Ababa, Ethiopia, $2016(n=418)$

\begin{tabular}{|c|c|c|c|}
\hline Variables & Category & Frequency & Per cent \\
\hline \multirow{2}{*}{$\begin{array}{l}\text { Age at onset of } \\
\text { illness }\end{array}$} & $\leq 25$ years & 255 & 61.0 \\
\hline & $>25$ years & 163 & 39.0 \\
\hline \multirow[t]{3}{*}{ Duration of illness } & $<5$ years & 147 & 35.2 \\
\hline & $5-10$ years & 114 & 27.3 \\
\hline & $>10$ years & 157 & 37.6 \\
\hline \multirow[t]{2}{*}{ Treatment duration } & $\leq 6$ years & 220 & 52.6 \\
\hline & $>6$ years & 198 & 47.4 \\
\hline \multirow[t]{2}{*}{ Number of episodes } & $<2$ & 167 & 40.0 \\
\hline & $\geq 2$ & 251 & 60.0 \\
\hline \multirow{2}{*}{$\begin{array}{l}\text { Presence of } \\
\text { hospitalisation }\end{array}$} & Yes & 218 & 52.2 \\
\hline & No & 200 & 47.8 \\
\hline \multirow{2}{*}{$\begin{array}{l}\text { Number of } \\
\text { hospitalisations }\end{array}$} & $<4$ & 175 & 41.9 \\
\hline & $\geq 4$ & 45 & 10.8 \\
\hline \multirow[t]{2}{*}{ Current episode } & Manic & 310 & 74.2 \\
\hline & Depressive & 108 & 25.8 \\
\hline \multirow{2}{*}{$\begin{array}{l}\text { Ever had traditional } \\
\text { treatment }\end{array}$} & Yes & 190 & 45.5 \\
\hline & No & 228 & 54.5 \\
\hline \multirow{2}{*}{$\begin{array}{l}\text { Family history of } \\
\text { mental illness }\end{array}$} & Yes & 119 & 28.5 \\
\hline & No & 299 & 71.5 \\
\hline \multirow{2}{*}{$\begin{array}{l}\text { Previous suicidal } \\
\text { attempt }\end{array}$} & Yes & 144 & 34.4 \\
\hline & No & 274 & 65.6 \\
\hline \multirow{2}{*}{$\begin{array}{l}\text { Ever had } \\
\text { discontinuation of } \\
\text { medication }\end{array}$} & Yes & 233 & 55.7 \\
\hline & No & 185 & 44.3 \\
\hline \multirow{2}{*}{$\begin{array}{l}\text { Contribution } \\
\text { of stigma to } \\
\text { discontinuation of } \\
\text { medication }\end{array}$} & Yes & 25 & 5.9 \\
\hline & No & 208 & 49.8 \\
\hline \multirow[t]{3}{*}{ Social support } & Poor & 176 & 42.1 \\
\hline & Intermediate & 148 & 35.4 \\
\hline & Strong & 94 & 22.5 \\
\hline \multirow[t]{2}{*}{ Self-esteem } & Low & 133 & 31.8 \\
\hline & High & 285 & 68.2 \\
\hline
\end{tabular}

previous hospitalisations, number of episodes and type of current episode, social support and low self-esteem were significantly associated with internalised stigma at $\mathrm{p}$ value less than 0.2 . These factors were entered into the multivariable logistic regression model to control confounding effects.

The result of the multivariate analysis showed that unemployed (AOR=2.3, 95\% CI: 1.0 to 5.0), unable to read and write (AOR=3.3, 95\% CI: 1.0 to 10.7), poor social support (AOR=5.3, 95\% CI: 1.9 to 15.0 ), previous hospitalisations ( $\geq 4$ times) (AOR=2.6, 95\% CI: 1.1 to 6.1 ) and low self-esteem (AOR=2.4, 95\% CI: 1.1 to 5.1) were significantly associated with internalised stigma (table 3 ).

\section{DISCUSSION}

This study found that a number of patients were experiencing internalised stigma. Some $24.9 \%$ of people with the disorder had internalised stigma according to ISMI scale. Our finding was consistent with reports of studies across 13 European countries, $21.7 \%^{10}$; in Shanghai, China, $24.2 \%{ }^{11}$; Iran, $26.7 \%^{12}$ and the USA, $28 \%{ }^{4}$

Conversely, this finding was lower than $33.7 \%$ noted in Nigeria, ${ }^{13} 38.7 \%$ in India, ${ }^{14} 46 \%$ in Turkey ${ }^{22}$ and $36 \%$ in the USA. ${ }^{15}$ The variation might be due to the difference in sample size and study subjects. In Turkey, they used only 100 participants, and in the USA patients with schizophrenia and other psychotic disorders were included in addition to patients with bipolar disorder. The inclusion of patients with schizophrenia disorder in that study may increase internalised stigma because of the continuous nature of the illness. The other variation might be that in our study most of the participants were from an urban setting and in college and had above educational level, which in turn reduces level of internalised stigma.

On the other hand, our finding was higher than $18.5 \%$ in Turkey. ${ }^{9}$ The discrepancy might be due to different study designs and study subjects they used. In Turkey, they used a comparative cross-sectional study design and all the participants were literate. This is due to the fact that those patients with lower educational status may have more internalised stigma.

The odds of internalised stigma among unemployed were 2.3 times higher than employed participants. This is consistent with the study conducted across 13 European countries, ${ }^{10}$ in Shanghai, China, ${ }^{11} \operatorname{Iran}^{12}$ and Jimma. ${ }^{23}$ Studies showed that unemployed persons were found to have higher stigma. ${ }^{28-30}$ They also have less self-tolerance and are resistant to stigma. As a result, patients might face problems related to employment opportunities, ${ }^{31-33}$ and be less likely to apply for jobs because they might be preoccupied with thoughts of being unable to achieve their jobs. ${ }^{34}$

Participants who could not read and write were 3.34 times more likely to experience internalised stigma compared with those in college and have above educational level. This is also supported by studies across 13 European countries, ${ }^{10}$ in Shanghai, China, ${ }^{11} \operatorname{Iran}^{12}$ and Turkey. ${ }^{9}$ High level of education might protect people from applying devaluing judgement to them. Literacy might also increase the possibility of using multiple sources of information to increase one's knowledge about 
Table 3 Bivarate and multivariate analysis of internalised stigma and explanatory variables among people with bipolar disorder at the outpatient department of Amanuel Mental Specialized Hospital, Addis Ababa, Ethiopia, 2016 ( $n=418)$

\begin{tabular}{|c|c|c|c|c|c|}
\hline \multirow[b]{2}{*}{ Variables } & \multicolumn{2}{|c|}{ Internalised stigma } & \multirow[b]{2}{*}{ COR $(95 \% \mathrm{Cl})$} & \multirow[b]{2}{*}{ AOR $(95 \% \mathrm{Cl})$} & \multirow[b]{2}{*}{$P$ value } \\
\hline & High & Low & & & \\
\hline \multicolumn{6}{|l|}{ Current working status } \\
\hline No & 49 & 105 & 1.8 (1.1 to 2.8$)$ & $2.3(1.0 \text { to } 5.1)^{\star}$ & 0.007 \\
\hline \multicolumn{6}{|l|}{ Residence } \\
\hline \multicolumn{6}{|l|}{ Marital status } \\
\hline Single & 64 & 159 & $1.5(0.9$ to 2.6$)$ & 1.86 (0.73 to 4.75$)$ & 0.356 \\
\hline Divorced or widowed & 13 & 52 & 1.0 (0.5 to 2.0$)$ & 0.4 (0.1 to 1.3$)$ & 0.871 \\
\hline Married & 27 & 103 & 1.0 & 1.0 & \\
\hline \multicolumn{6}{|l|}{ Ever had traditional treatment } \\
\hline \multicolumn{6}{|l|}{ Educational status } \\
\hline Unable to read and write & 24 & 38 & $2.2(1.1$ to 4.4$)$ & $3.3(1.1 \text { to } 10.7)^{\star}$ & 0.016 \\
\hline Primary & 24 & 79 & $1.1(0.6$ to 2.0$)$ & 1.6 (0.6 to 4.3$)$ & 0.913 \\
\hline Secondary & 31 & 109 & $1.0(0.6$ to 1.8$)$ & 0.8 (0.3 to 2.2$)$ & 0.238 \\
\hline College and above & 25 & 88 & 1.0 & 1.0 & \\
\hline \multicolumn{6}{|l|}{ Current episode } \\
\hline Manic & 84 & 226 & 1.0 & 1.0 & \\
\hline Depressive & 20 & 88 & 0.6 (0.4 to 1.1$)$ & 1.3 (0.4 to 3.9$)$ & 0.332 \\
\hline \multicolumn{6}{|l|}{ Number of episodes } \\
\hline \multicolumn{6}{|l|}{ Self-esteem } \\
\hline Low & 45 & 88 & 2.0 (1.2 to 3.1$)$ & $2.3(1.1 \text { to } 5.1)^{\star}$ & 0.001 \\
\hline High & 59 & 226 & 1.0 & 1.0 & \\
\hline \multicolumn{6}{|l|}{ Previous hospitalisation } \\
\hline$<4$ & 38 & 137 & 1.0 & 1.0 & \\
\hline$\geq 4$ & 20 & 25 & 2.9 (1.5 to 5.8$)$ & $2.6(1.1 \text { to } 6.1)^{\star}$ & 0.031 \\
\hline \multicolumn{6}{|l|}{ Social support } \\
\hline Poor & 67 & 109 & $2.8(1.5$ to 5.1$)$ & $5.3(1.9 \text { to } 15.0)^{\star \star}$ & 0.002 \\
\hline Intermediate & 20 & 128 & 0.7 (0.4 to 1.4$)$ & 1.1 (0.4 to 3.2$)$ & 0.938 \\
\hline Strong & 17 & 77 & 1.0 & 1.0 & \\
\hline
\end{tabular}

${ }^{*} \mathrm{P}<0.05,{ }^{* *} \mathrm{p}<0.01$, Hosmer-Lemeshow test $=0.78$.

AOR, adjusted OR; COR, crude OR.

mental illness. Conversely, people who could not read and write might relate the cause of their mental illness to supernatural explanations like demon possessions, or bewitchment by an evil spirit, ancestor's spirit or evil eye, which might contribute to increased internalised stigma. $^{23}$
This study found that participants who had more than three hospital admissions have higher internalised stigma than those who had less number of hospital admissions. This is supported by results of a study conducted in India. ${ }^{14}$ Repeated hospitalisations in the past might show the seriousness of the patients' symptom that could 
be easily seen by the public and exposed the patient to public stigma. Repeated absences from social situations because of frequent hospitalisations might also make the patients easily stigmatised.

Regarding social support, the odds of developing internalised stigma were 5.3 times higher among patients with poor social support compared with those with strong social support. People with good social support might have increased self-esteem which conversely reduces stigma. Moreover, patients with good social support might have good medication adherence which contributes to controlling of symptoms. This finding was consistent with other study findings. ${ }^{16}$

Concerning self-esteem, patients who had low selfesteem were 2.4 times more likely to develop internalised stigma than patients with high self-esteem. This finding was supported by results of studies conducted in various countries. ${ }^{35-38}$ Patients with severe mental illness could have low self-esteem which reduces their ability to resist stigma. $^{35}$

\section{Limitation of the study}

The cross-sectional design of the study prevented us from concluding the causal relationships of the associations we found.

Social desirability and recall bias might also be the other limitations, since the data collection method was a face-to-face interview, which might lead individuals to respond in socially acceptable ways during the process.

The findings of this study could not be generalised to patients in other health facilities.

The tool, ISMI, was not validated although it was widely used as a screening tool for internalised stigma in Ethiopia.

\section{CONCLUSION}

In the current study, more than one-fourth of the sample experienced high internalised stigma. Unemployment, low educational status, $\geq 4$ previous hospitalisations, poor social support and low self-esteem had a significant association with internalised stigma. Thus, it is necessary to give emphasis on a stigma-reduction programme to improve individuals' self-esteem and stigma-resistance capability, and expand their social support.

\section{Author affiliations \\ ${ }^{1}$ Department of Psychiatry, College of Medicine and Health Sciences, University of Gondar, Gondar, Ethiopia \\ ${ }^{2}$ Department of Psychiatry, Amanuel Mental Specialized Hospital, Addis Ababa, Ethiopia \\ ${ }^{3}$ Department of Epidemiology and Biostatics, College of Medicine and Health Sciences, University of Gondar, Gondar, Ethiopia \\ ${ }^{4}$ Department of Psychiatry, College of Medicine and Health Sciences, Bahir Dar University, Bahir Dar, Ethiopia \\ ${ }^{5}$ Department of Psychiatry, Debre Berhan University, Debre Berhan, Ethiopia}

Acknowledgements The authors acknowledge the University of Gondar and Amanuel Mental Specialized Hospital for funding the study. We extend our gratitude to data collectors, supervisors and study participants for their time and effort. We also thank Mr Demeke Dessu for his great contribution to language editing of the manuscript.

Contributors NA developed the proposal, supervised the data collection, analysed the data and wrote the draft of the manuscript. BW and TE revised the proposal and checked the data analysis. SS and DA revised the proposal, checked the data analysis, revised and approved the manuscript.

Funding The authors have not declared a specific grant for this research from any funding agency in the public, commercial or not-for-profit sectors.

Competing interests None declared.

Patient consent for publication Not required.

Ethics approval Approval was obtained from the joint Ethical Review Committees of the University of Gondar and Amanuel Mental Specialized Hospital. We received written informed consent from study participants after explaining the purpose of the study. Confidentiality was maintained by omitting personal identifiers.

Provenance and peer review Not commissioned; externally peer reviewed.

Data availability statement No data are available. All the data are included in the manuscript and no additional data available.

Open access This is an open access article distributed in accordance with the Creative Commons Attribution Non Commercial (CC BY-NC 4.0) license, which permits others to distribute, remix, adapt, build upon this work non-commercially, and license their derivative works on different terms, provided the original work is properly cited, appropriate credit is given, any changes made indicated, and the use is non-commercial. See: http://creativecommons.org/licenses/by-nc/4.0/.

\section{ORCID iDs}

Shegaye Shumet http://orcid.org/0000-0001-7714-7455

Dessie Angaw http://orcid.org/0000-0001-9827-2255

\section{REFERENCES}

1 Bobak M, Powles J. Poverty and non-communicable diseases in central and eastern Europe, with implications for surveillance. A report for the non-communicable diseases and mental health cluster, who, Geneva. Geneva: Word Health Organisation, and London: University College London, 2001.

2 Scheyett A. The mark of madness: stigma, serious mental illnesses and social work. Social Work in Mental Health 2005;3:79-97.

3 Corrigan PW, Kerr A, Knudsen L. The stigma of mental illness: explanatory models and methods for change. Applied and Preventive Psychology 2005;11:179-90.

4 Ritsher JB, Otilingam PG, Grajales M. Internalized stigma of mental illness: psychometric properties of a new measure. Psychiatry Res 2003;121:31-49.

5 Corrigan PW, Watson AC, Barr L. The self-stigma of mental illness: implications for self-esteem and self-efficacy. J Soc Clin Psychol 2006;25:875-84.

6 Goodwin FK, Jamison KR. Manic-Depressive illness: bipolar disorders and recurrent depression. Oxford University Press, 2007.

7 Ferrari AJ, Stockings E, Khoo J-P, et al. The prevalence and burden of bipolar disorder: findings from the global burden of disease study 2013. Bipolar Disord 2016;18:440-50.

8 Murray CJ, Lopez AD. Evidence-based health policy--lessons from the Global Burden of Disease Study. Science 1996;274:740-3.

9 Sarısoy G, Kaçar Ömer Faruk, Pazvantoğlu O, et al. Internalized stigma and intimate relations in bipolar and schizophrenic patients: a comparative study. Compr Psychiatry 2013;54:665-72.

10 Brohan E, Gauci D, Sartorius N, et al. Self-stigma, empowerment and perceived discrimination among people with bipolar disorder or depression in 13 European countries: the GAMIAN-Europe study. J Affect Disord 2011;129:56-63.

11 Z-g WU, C-m Y, WANG Z. Self-stigma in patients with mood disorders and its related factors. Journal of Shanghai Jiaotong University 2011;31.

12 Sadighi G, Khodaei MR, Fadaie F. Self stigma among people with bipolar-I disorder in Iran. Iran Rehabil J 2015;13:32-28.

13 Ibrahim A, Mukhtar Y, Sadique P, et al. A facility-based assessment of internalized stigma among patients with severe mental illnesses in Maiduguri, north-eastern Nigeria. Int Neuropsychiatr Dis J 2016:6:1-11.

14 James TT, Kutty VR, VRJAPJoPH K. Assessment of internalized stigma among patients with mental disorders in Thiruvananthapuram district, Kerala, India. Asia Pac J Public Health 2015;27:439-49. 
15 West ML, Yanos PT, Smith SM, et al. Prevalence of internalized stigma among persons with severe mental illness. Stigma Res Action 2011;1:3.

16 Adewuya AO, Owoeye AO, Erinfolami AO, et al. Correlates of selfstigma among outpatients with mental illness in Lagos, Nigeria. Int $J$ Soc Psychiatry 2011;57:418-27.

17 Ritsher JB, Phelan JC. Internalized stigma predicts erosion of morale among psychiatric outpatients. Psychiatry Res 2004;129:257-65.

18 Rusch LC, Kanter JW, Manos RC, et al. Depression stigma in a predominantly low income African American sample with elevated depressive symptoms. J Nerv Ment Dis 2008;196:919-22.

19 Manos RC, Rusch LC, Kanter JW, et al. Depression self-stigma as a mediator of the relationship between depression severity and avoidance. J Soc Clin Psychol 2009;28:1128-43.

20 Cooper AE, Corrigan PW, Watson AC. Mental illness stigma and care seeking. J Nerv Ment Dis 2003;191:339-41.

21 Corrigan PW, Watson AC. The paradox of self-stigma and mental illness. Clinical Psychology: Science and Practice 2002;9:35-53.

22 Üstündağ MF, Kesebir S. [Internalized stigmatization in bipolar patients: relationship with clinical properties, quality of life and treatment compliance]. Turk Psikiyatri Derg 2013;24:231-9.

23 Girma E, Tesfaye M, Froeschl G, et al. Facility based cross-sectional study of self stigma among people with mental illness: towards patient empowerment approach. Int J Ment Health Syst 2013;7:21.

24 Serafini G, Pompili M, Haghighat R, et al. Stigmatization of schizophrenia as perceived by nurses, medical doctors, medical students and patients. J Psychiatr Ment Health Nurs 2011;18:576-85.

25 Kamaradova D, Latalova K, Prasko J, et al. Connection between selfstigma, adherence to treatment, and discontinuation of medication 2016;10:1289-98.

26 Asnakew S, Shumet S, Ginbare W, et al. Prevalence of posttraumatic stress disorder and associated factors among Koshe landslide survivors, Addis Ababa, Ethiopia: a community-based, cross-sectional study. BMJ Open 2019;9:e028550.
27 Robins RW, Hendin HM, Trzesniewski KH. Measuring global selfesteem: construct validation of a single-item measure and the Rosenberg self-esteem scale. Pers Soc Psychol Bull 2001;27:151-61.

28 Alonso J, Buron A, Rojas-Farreras S, et al. Perceived stigma among individuals with common mental disorders. J Affect Disord 2009;118:180-6.

29 Angermeyer MC. [The stigma of mental illness from the patient's view--an overview]. Psychiatr Prax 2003;30:358-66.

30 Corrigan P, Thompson V, Lambert D, et al. Perceptions of discrimination among persons with serious mental illness. Psychiatr Serv 2003;54:1105-10.

31 Van Brakel WH. Measuring health-related stigma--a literature review. Psychol Health Med 2006;11:307-34.

32 Roeloffs C, Sherbourne C, Unützer J, et al. Stigma and depression among primary care patients. Gen Hosp Psychiatry 2003;25:311-5.

33 Wahl OF. Mental health consumers' experience of stigma. Schizophr Bull 1999;25:467-78.

34 Loganathan S, Murthy SR. Experiences of stigma and discrimination endured by people suffering from schizophrenia. Indian J Psychiatry 2008;50:39.

35 Yanos PT, Roe D, Markus K, et al. Pathways between internalized stigma and outcomes related to recovery in schizophrenia spectrum disorders. PS 2008;59:1437-42.

36 Mashiach-Eizenberg M, Hasson-Ohayon I, Yanos PT, et al. Internalized stigma and quality of life among persons with severe mental illness: the mediating roles of self-esteem and hope. Psychiatry Res 2013;208:15-20.

37 Tang I-C, Wu H-C, H-CJPq W. Quality of life and self-stigma in individuals with schizophrenia. Psychiatr Q 2012;83:497-507.

38 Kranke DA, Floersch J, Kranke BO, et al. A qualitative investigation of self-stigma among adolescents taking psychiatric medication. $P S$ 2011;62:893-9. 